\title{
Experiências do PIBID/UERN: relatos pedagógicos com alunos do Ensino Fundamental I
}

\author{
Experiences of PIBID/UERN: pedagogical reports with \\ Elementary School I students
}

Experiencias del PIBID/UERN: informes pedagógicos com estudiantes del Educación Primaria I

Lidiane Alves da Cunha ${ }^{1}$ João Paulo Jales dos Santos ${ }^{2}$

\section{RESUMO}

O presente trabalho relata experiências a partir de práticas pedagógicas de alunos bolsistas do PIBID, da modalidade interdisciplinar. As atividades, estruturadas na formação inicial de professores, foram desenvolvidas no âmbito do Ensino Fundamental I, na escola Estadual Jerônimo Vingt Rosado Maia, na cidade de Mossoró/RN. O objeto de estudo em análise reside na interação dos bolsistas com as crianças a partir das atividades desenvolvidas na instituição escolar, sob a égide do PIBID, no ano de 2017. Utilizando-se de uma metodologia qualitativa, a narrativa, o artigo tem como objetivo compartilhar relatos de discentes em suas experiências de desenvolvimento de atividades de um programa de suma importância para a graduação, o PIBID, demonstrando o mérito da atuação 'in loco' que graduandos vivenciaram no decorrer das práticas pedagógicas, que envolveram um mútuo processo de ensino-aprendizagem entre bolsistas e crianças.

Palavras-chave: Escola Estadual Jerônimo Vingt Rosado Maia. Formação inicial de professores. PIBID interdisciplinar. Relatos pedagógicos.

\section{ABSTRACT}

This paper reports experiences from the pedagogical practices of PIBID scholarship students, of the interdisciplinary modality. The activities, structured in the initial formation of teachers, were developed in the scope of Elementary Education I, at the Jerônimo Vingt Rosado Maia State School, in the city of Mossoró/RN. The object of study under analysis is the interaction of the scholarship students with the children from the activities developed in the school institution, under the aegis of PIBID, in 2017. Using a qualitative methodology, the narrative, the article aims to share reports of students in

\footnotetext{
${ }^{1}$ Universidade do Estado do Rio Grande do Norte. Doutora em Ciências Sociais pela Universidade Federal do Rio Grande do Norte. Professora do curso de Ciências Sociais da Universidade do Estado do Rio Grande do Norte, Mossoró, RN, Brasil. E-mail: lidianeadc@gmail.com/ ORCID: https://orcid.org/0000-0003-2161-9446

2 Universidade do Estado do Rio Grande do Norte. Graduado no curso de Ciências Sociais (licenciatura) pela Universidade do Estado do Rio Grande do Norte (UERN). E-mail: joaao.joaaopaulo@gmail.com/ ORCID: https://orcid.org/0000-0003-0037-3571
} 
their experiences of developing activities of a program of great importance for undergraduate, PIBID, demonstrating the merit of the 'on-site' performance that undergraduates experienced during the pedagogical practices, which involved a mutual teaching-learning process between scholars and children.

KEYWORDS: Jerônimo Vingt Rosado Maia State School. Initial formation of teachers. Interdisciplinary PIBID. Pedagogical reports.

\section{RESUMEN}

El presente trabajo reporta experiencias de las prácticas pedagógicas de los becarios PIBID, de la modalidad interdisciplinaria. Las actividades, estructuradas en la formación inicial de los docentes, se desarrollaron en el ámbito de la Educación Primaria I, en la Escuela Estatal Jerônimo Vingt Rosado Maia, en la ciudad de Mossoró/RN. El objeto de estudio bajo análisis radica en la interacción de los becarios con los niños de las actividades desarrolladas en la institución escolar, bajo el auspicio del PIBID, en el año 2017. Usando una metodología cualitativa, la narrativa, el artículo tiene como objetivo compartir los informes de los estudiantes sobre sus experiencias de desarrollo de actividades en un programa de suma importancia para el programa de pregrado, PIBID, demostrando el mérito de la actuación "in loco" que experimentaron los estudiantes en el curso de las prácticas pedagógicas, que implicó un proceso de enseñanza-aprendizaje mutuo entre los becarios y los niños.

Palabras clave: Escuela Estatal Jerônimo Vingt Rosado Maia. Formación inicial docente. PIBID interdisciplinario. Informes pedagógicos.

\section{Introdução}

A presente pesquisa relata experiências a partir de atividades realizadas por bolsistas do Programa Institucional de Bolsas de Iniciação à Docência (PIBID), que tiveram a oportunidade de compreender, através do programa, o importante alicerce para a formação acadêmico-docente, compreendendo que a inserção durante a graduação no espaço escolar constitui ponto de extrema relevância na capacitação teórico-prática do licenciando.

Os bolsistas do PIBID interdisciplinar, da Universidade do Estado do Rio Grande do Norte (UERN), trabalharam com crianças do $1^{\circ}$ ao $5^{\circ}$ ano do Ensino Fundamental I. Ressalta-se que o PIBID interdisciplinar reunia estudantes provenientes de diferentes cursos de graduação, onde alguns bolsistas tiveram contato com a educação de crianças pela primeira vez. As ações do subprojeto interdisciplinar tinham como fundamento o objetivo e a justificativa do subprojeto, que tinha o norteamento da temática, "A educação ambiental na perspectiva da promoção da saúde como eixo articulador da formação interdisciplinar". Conforme a própria justificativa do subprojeto:

O projeto "A educação ambiental na perspectiva da promoção da saúde 
como eixo articulador da formação interdisciplinar" traz como como objeto, o papel formativo da educação ambiental e da promoção da saúde, enquanto conhecimentos que se articulam em função de objetivos comuns. A problemática ambiental constitui-se em um dos temas mais relevantes da atualidade. 0 processo de desenvolvimento tem aprofundado os problemas ambientais e a Universidade, enquanto espaço de formação tem um compromisso com a sustentabilidade ambiental. Este compromisso ainda não representa uma realidade consolidada nos diversos curso da nossa IES. Constatando-se essa realidade propomos um subprojeto que amplie a formação docente inserindo a abordagem da temática proposta em cursos de licenciatura e nas escolas parceiras. Esse projeto interdisciplinar pretende identificar os nexos entre a formação específica de cada curso, descobrindo o que determina a proposta curricular em relação a educação ambiental e saúde, elaborando a partir do diagnóstico, estudos teóricos e experiências e proposições para essa abordagem pelos professores do ensino básico, bem como no âmbito das licenciaturas. Essa proposta não está restrita a dimensão ecológica, mas recupera o princípio de totalidade considerando o ser humano como parte do meio ambiente e afetado com problemas que não sendo ecológicos são socioambientais, tais como o racismo, a homofobia, o machismo, dentre outros que impedem a sadia qualidade de vida (SUBPROJETO..., 2013, p.2).

Como as experiências do PIBID interdisciplinar na escola Estadual Jerônimo Vingt Rosado Maia impactaram no processo de formação docente dos bolsistas da Universidade do Estado do Rio Grande do Norte (UERN)? Como a diversidade de graduandos de diferentes cursos gerou trocas contínuas de aprendizagem, tanto nos bolsistas, quanto nas crianças envolvidas nas atividades do PIBID? São estas perguntas que o trabalho procurará responder.

A escola Estadual Jerônimo Vingt Rosado Maia está localizada no conjunto Vingt Rosado, a instituição oferta o ciclo do Ensino Fundamental nos turnos matutino e vespertino. Pelo turno matutino funciona o Ensino Fundamental I, no qual os bolsistas realizaram as atividades. No turno vespertino funciona o Ensino Fundamental II. A escola ainda trabalha com a Educação de Jovens e Adultos (EJA), no turno noturno. As ações do PIBID na escola se deram na dualidade, planejamentoexecução, ocorrendo ao longo do ano de 2017, período de atividades que se deterá o artigo, onde foram realizadas doze ações na escola.

Ressalta-se que o PIBID interdisciplinar, do Campus Central da UERN, realizava suas atividades desde o ano de 2014, quando foi aprovado pela Coordenação de Aperfeiçoamento de Pessoal de Nível Superior (CAPES), seguindo os critérios do edital no 061/2013. O último ano das ações na escola Jerônimo Vingt Rosado Maia foi o ano de 2017, no qual se justifica ser o ano a ter as ações relatadas na pesquisa. O edital da CAPES no 061/2013, que tinha um fluxo contínuo, foi encerrado em janeiro de 2018, quando já no governo de Michel Temer, que decidiu interromper o edital para reformular o PIBID.

No momento da execução do que fora planejado é que se detém o objeto proposto a ser analisado. A interação entre bolsistas e alunos constitui circunstância em que o contato com as crianças torna possível que o planejado possa ser efetivamente executado como fora pensado. Corsaro (2009), compreende que as 
crianças assimilam criativamente informações do mundo adulto para construírem culturas singulares. Para o autor, as culturas de pares infantis são entendidas como "um conjunto de atividades ou rotinas, artefatos, valores e preocupações que as crianças produzem e partilham na interação com os seus pares" (CORSARO, 2009, p.32).

A interação bolsistas-alunos não envolveu somente aspectos puramente institucionais, acabou por envolver um caráter de aproximação relacional entre bolsistas e crianças, onde se pôde conhecer alguns aspectos da realidade destas. E nessa relação o viés do afeto em muitos momentos se fez presente. Seja através de um abraço carinhoso, de um amparo para que a condição de vulnerabilidade social dos alunos fosse de algum modo acalentada, por uma atenção especial por parte dos bolsistas.

Como afirma Vigotskii (2010) o desenvolvimento do indivíduo é um processo construído nas e pelas interações que o indivíduo estabelece no contexto histórico e cultural em que está inserido. Com isso, o espaço escolar se torna um ambiente onde as crianças, ao estabelecerem uma relação com os bolsistas, mostraram de algum modo o tipo de ambiente em que conviviam em casa. A mediação acontece por meio de instrumentos e signos que se interpõem entre o sujeito e o objeto de sua atividade em busca de novas aprendizagens e consequente desenvolvimento (FACCI, 2004).

Valendo-se do uso do método qualitativo de narrativas, a pesquisa recorre a esse método para amparar os relatos pedagógicos, bem como descrever as relações que aconteceram entre bolsistas e crianças, pois se compreende que nestas relações, entre o objetivo institucional do PIBID e a subjetividade das crianças:

Pesquisa Narrativa é uma forma de compreender a experiência. É um tipo de colaboração entre pesquisadores e participantes, ao longo de um tempo, em um lugar ou série de lugares, e em interação como milieus. Um pesquisador entra nessa matriz no durante e progride no mesmo espírito, concluindo a pesquisa ainda no meio do viver e do contar, do reviver e do recontar; as histórias de experiências que compuseram as vidas das pessoas, em ambas as perspectivas: individual e social (CLANDININ; CONNELLY, 2011, p.51).

As crianças da escola Jerônimo Vingt Rosado Maia, via de regra, se encontram em situação de vulnerabilidade social, pertencentes aos estratos socioeconômicos baixos. Tal observação fica evidente na localização da escola, que está situada numa área periférica da cidade de Mossoró, o conjunto Vingt Rosado, carente de equipamentos e serviços sociais, onde o Poder Público precariamente faz articulação de políticas públicas. A esse aspecto governamental, soma-se que o contato entre alunos e bolsistas, acarretou com que estes, pudessem perceber a realidade socioeconômica das crianças através do diálogo permanente que o contato das atividades proporcionou.

Da relação entre graduandos e crianças surge a faceta institucional do PIBID, a formação docente, tema contumaz em debates acadêmicos, institucionais e de diferentes setores da sociedade civil preocupados com a temática. O PIBID, enquanto programa alicerçado em contemplar bolsas para que estudantes atuem na escola, constitui ensinamento imprescindível para inserir o graduando no futuro espaço de atuação profissional. Através desta vivência, o aluno passa a conhecer e compreender os desafios que terá quando estiver exercendo o magistério. O PIBID contempla para 
o aluno a construção de sua identidade profissional, colocando a teoria das aulas e dos livros em dialética com a prática docente. Como presente no decreto no 7.219 que regulamentou o PIBID:

Art. 10 O Programa Institucional de Bolsa de Iniciação à Docência PIBID, executado no âmbito da Coordenação de Aperfeiçoamento de Pessoal de Nível Superior - CAPES, tem por finalidade fomentar a iniciação à docência, contribuindo para o aperfeiçoamento da formação de docentes em nível superior e para a melhoria de qualidade da educação básica pública brasileira (BRASIL, 2010).

Neste sentido, cabe ao PIBID interdisciplinar, eixo estruturante da modalidade da qual os graduandos estiveram sob égide, uma peculiaridade ímpar, ao reunir diferentes cursos em uma mesma escola, acabou por propiciar um debate enriquecedor, onde diferentes visões pedagógicas convergiram para que a qualidade das tarefas pudesse almejar um diálogo profícuo no desenvolvimento das ações. Para fins elucidativos, no eixo estruturante interdisciplinar, os discentes do turno matutino que trabalharam na escola Jerônimo Vingt Rosado Maia, são provenientes das seguintes licenciaturas: Ciências Biológicas, Ciências Sociais, Geografia e Pedagogia.

$\mathrm{Na}$ experiência escolar, pôde-se perceber através das atividades o quão mútuo é o processo de ensino-aprendizagem. Graduandos e crianças puderam desfrutar de trocas de informações e assimilações que tornaram prazerosas as ações que foram pensadas para o contexto do Ensino Fundamental I, evidenciando o alcance da perspectiva pedagógica do PIBID, ao permitir que diferentes visões pedagógicas se agrupassem e canalizassem uma pedagogia da práxis no ato das tarefas. Eis uma instância íntima do PIBID, fazer com que a formação docente dos bolsistas esteja em contínua dialética com os saberes pedagógicos, com os indivíduos envolvidos em todo o processo das atividades, com os desafios encontrados na instituição escolar e com o momento de concretização das ideias propostas. Como diz Zabala:

Um dos objetivos de qualquer bom profissional consiste em ser cada vez mais competente em seu ofício. Geralmente se consegue esta meIhoria profissional mediante o conhecimento e a experiência: o conhecimento das variáveis que intervêm na prática e a experiência para dominá-las (ZABALA, 1998, p.13).

Neste contato entre a escola e o PIBID interdisciplinar, se percorre aquilo que nesta pesquisa denominar-se-á de relatos pedagógicos. E o que são estes relatos? São notas que a partir da experiência do PIBID formam a espinha dorsal das vivências que se deram na escola. São relatos de experiências que fizeram com que os bolsistas compreendessem a elaboração da teoria, aliada a prática do saber pedagógico. Como bem observa Freire:

Rigorosidade metódica, pesquisa, respeito aos saberes dos educandos, criticidade, ética e estética, corporificar as palavras pelo exemplo, assumir riscos, aceitar o novo, rejeitar qualquer forma de discriminação, reflexão crítica sobre a prática, reconhecimento e assunção da identidade cultural, ter consciência do inacabamento, reconhecer-se como um ser condicionado, respeitar autonomia do ser educando, bom senso, 
humildade, tolerância, convicção de que mudar é possível, curiosidade, competência profissional (FREIRE, 1996, p.14).

Alicerçada numa reflexão da importância de um fazer pedagógico centrado no ensino, e no sujeito que faz parte deste processo, percebendo-o como sujeito ativo, que pensa, que sente e que age sobre o meio ao qual está inserido, e na escola como um ambiente aonde se configura o panorama pedagógico, têm-se os saberes que ao longo das tarefas dos "pibidianos" ajudaram a nortear a experiência do impacto formativo-acadêmico na instituição Jerônimo Vingt Rosado Maia. Junto com a formação inicial docente dos bolsistas, acabam por constituírem o cerne teóricometodológico da pesquisa.

De teor descritiva, consolidada no uso de metodologia qualitativa, esta pesquisa, direciona-se a professores, graduandos e demais interessados na docência, que terão nos relatos a oportunidade de comprovar o quão bem funciona o PIBID inserido numa escola, formando professores e contribuindo para o ensinoaprendizagem dos envolvidos nos processos pedagógicos da rotina do programa.

\section{A escola como um lugar social, aberta a novas experiências}

A educação pode ser promovida nos mais diversos lugares da sociedade. Numa abordagem da educação no âmbito escolar, compreende-se que a escola contemporânea deve ser um lugar aberto a novas experiências, a novas descobertas. Ao proporcionar isto, faz com que o aluno se desenvolva de forma mais significativa.

A instituição de ensino é um dos primeiros ambientes no qual a criança começa a desenvolver suas relações interativas, nisso é indispensável que o professor esteja atento à realidade social de cada aluno. Deve-se levar em consideração a diversidade que existe nesse espaço tão plural que é a escola, pois o conceito de cidadania está inerente ao respeito pelo próximo e por aquilo que é diferente da nossa maneira de pensar e descrever o mundo.

O contato entre sujeitos, com o mundo que os cercam, traz aprendizados fundamentais para a vida. Nesse contexto, o processo de ensino-aprendizagem se concretiza através das experiências cotidianas nos ambientes de ensino. A familiaridade que se adquire ao conhecer a realidade dos sujeitos propicia um amadurecimento em relação ao olhar da formação da carreira docente.

Não se pode pensar que se aprende apenas com um professor. Mesmo sabendo que este é uma peça essencial no processo de ensino-aprendizagem. Um olhar mais amplo, evidencia que os alunos aprendem com a pessoa que está desde o portão da escola, as recebendo, como também com as pessoas da cozinha, da limpeza, com os seus colegas no pátio, relações que constituem aprendizados formativos no ambiente escolar. Os alunos aprendem com todos que são integrantes da escola, todos que a fazem funcionar, ao mesmo tempo que aprende do seu modo, também ensina. Emerenciana diz que:

Educar é mostrar que a inter-relação, a parceria, a colaboração são fundamentais para o crescimento pessoal e da comunidade. Educar é 
despertar no homem a possibilidade da ação comprometida com o interpessoal e a consciência de que toda ação tem reflexo para além do pessoal e atinge os que estão ao seu redor (EMERENCIANA, 1996, p.140).

A educação vai acontecendo a partir desta relação com os outros, e nesta convivência é imprescindível que haja no sujeito um crescimento de amadurecimento emocional, despertando no sujeito a possibilidade de ação. A criança precisa estar inserida no mundo e compartilhar experiências com outras pessoas para a sua construção de conhecimento, como nos alerta Freire:

O conhecimento, pelo contrário, exige uma presença curiosa do sujeito face ao mundo. Requer sua ação transformadora sobre a realidade. Demanda uma busca constante. Implica em invenção e em reinvenção. Reclama a reflexão crítica de cada um sobre o ato mesmo de conhecer, pelo qual se reconhece conhecendo e, ao reconhecer-se assim, percebe o "como" de seu conhecer e os condicionamentos a que está submetido seu ato (FREIRE, 1979, p.27).

É estando convivendo com os outros e tendo contato com diferentes visões de mundo, que o sujeito se transforma, se conhece, se percebe como ser social. A convivência com as outras pessoas, além de possibilitar aprender novos conhecimentos diariamente com as situações que acontecem, ajuda também a refletir sobre as pessoas. Saber conviver com o próximo é fundamental, construindo com os alunos as melhores maneiras de convivência harmônica, alcançando bom senso em comum acordo. Essa aproximação com os alunos serve para reforçar uma convivência com base na confiança. Nisso é essencial que o docente desenvolva métodos educativos para poder alcançar êxito nas relações com seus educandos.

"Saber conviver, colaborar e compartilhar experiências e ideias uns com os outros é uma preparação para a vida democrática e, ao mesmo tempo, permite uma boa inserção na aula e no mundo social” (PARRAT-DAYAN, 2008, p.130).

O compartilhamento de ideias e experiências com os outros, nos prepara para a vida social, com esta relação vamos percebendo as nossas diferenças e semelhanças com os demais, entendendo a subjetividade de cada sujeito e respeitando-as. É a partir do convívio que se adquire a oportunidade de discernir sobre os fenômenos existentes nas instituições escolares. Nessa perspectiva, o que reforça esses elementos é a trajetória pautada nas manifestações dos sujeitos nesses espaços. Saber conviver, requer uma maturidade diante da realidade objetiva.

Nas experiências tidas com as crianças a partir do convívio, os bolsistas do PIBID perceberam o quanto o professor aprende com seus educandos, cada um com o seu modo singular e suas especificidades. A subjetividade do sujeito vai sendo constituída no sentido individual (consigo mesmo), e no sentido social (com o outro). Como nos afirma González Rey:

La relación entre subjetividad social e individual es mucho más compleja y contradictoria, por lo que el comportamiento del individuo se expresa con diversas contradicciones entre sus necesidades individuales y sociales, en las que deben asignar significado para mantener su desarrollo personal en medio de su expresión social. Entre 
Mesmo que as experiências que serão relatadas nesta pesquisa tenham sido um projeto desenvolvido na escola, não especificamente em sala de aula, o contato direto com os alunos oportunizou perceber o aprendizado e a reflexão que por ora se fala; pois, ao planejar, e posteriormente executar uma ação, percebia-se o que elas causavam nos alunos, fazendo os bolsistas refletirem, notando e compreendendo a expansão do saber pedagógico.

A escola é um órgão vivo, feita por aqueles que participam de forma direta ou indireta deste espaço, por isso a importância de se ter um olhar reflexivo. O conhecimento crítico-reflexivo propicia pensar os diagnósticos sociais por meio da alteridade. Para que isso ocorra, é necessário que se abandone os conceitos pejorativos e preconceituosos, tendo em vista que através da empatia se consegue enxergar e refletir sobre o outro e sobre a complexidade do mundo. Segundo Bondía (2002), a experiência é aquilo que nos passa, o que nos acontece, o que nos toca. Alguém não é experiente porque se sabe sobre muitos conteúdos, não se ganha experiência somente com o trabalho. Experiência não é somente o saber da prática. A Experiência requer:

[...] um gesto de interrupção, um gesto que é quase impossível nos tempos que correm: requer parar para pensar, para olhar, para escutar, pensar mais devagar, olhar mais devagar e escutar mais devagar; para sentir, sentir mais devagar, demorar-se nos detalhes, suspender a opinião, suspender o juízo, suspender a vontade, suspender o automatismo da ação, cultivar a atenção e a delicadeza, abrir os olhos e os ouvidos, falar sobre o que nos acontece, aprender a lentidão, escutar aos outros, cultivar a arte do encontro, calar muito, ter paciência e dar-se tempo e espaço (BONDÍA, 2002, p.24).

Com as experiências acumuladas, a mente e o corpo atribuem sentido aos acontecimentos. O mundo é um lugar de experiências, onde o corpo e a mente ao interagir percebem-se entre si, descobrindo um novo olhar de mundo, produzindo cultura, se construindo e reconstruindo. Amparando-se nestas teorias, enquanto sujeitos, nós bolsistas do PIBID, estivemos imersos em sentimentos e sensações que se fazem presentes no âmbito escolar. O contato humano traz consigo elementos sentimentais que tocam no íntimo emocional dos sujeitos envolvidos nos processos relacionais. Para além de uma atuação estritamente institucional, a escola é um espaço que envolve valores, éticas e ideias, conceitos que guiam os sujeitos presentes neste ambiente. A abstração que está envolta os valores e ideologias das pessoas, repercute nas condutas individuais, impactando a esfera coletiva.

Nós bolsistas nos vimos constantemente tocados por sentimentos, que nos foge ao alcance, pois não há como não se envolver em relações constituídas na escola, as ocasionadas juntamente com as crianças. Estas, pertencentes a camadas sociais vulneráveis, trazem para dentro da escola um pouco daquilo que vivenciam no meio onde vivem.

$\mathrm{Na}$ escola Jerônimo Vingt Rosado Maia, esteve presente essa confluência de realidades sociais que as crianças traziam de suas casas, das instituições sociais que 
frequentavam, e que, portanto, formavam o perfil humano de cada sujeito. Desse modo, não houve como nós bolsistas não nos sentirmos envolvidos com as emoções disso advindas. Seja numa forma de abraço, onde sentia-se que a criança esperava um aconchego que não tinha em casa. Seja nas falas das crianças, que nos introduziam em suas realidades.

A escola se transformou num lugar em que o contato entre bolsistas e alunos gerou um aprendizado social-emotivo, fazendo com que a empatia pudesse ser gestada e que olhares de reflexão pudessem ser compartilhados, melhorando de sobremodo o desenvolvimento das atividades do PIBID. Desde já se enfatiza que esse contato com os alunos serviu para amadurecer e aprimorar tanto a formação docente, como as subjetividades diante dos fatos vividos e presenciados.

\section{Relatos pedagógicos: as experiências do PIBID na Escola Estadual Jerônimo Vingt Rosado Maia}

Como relatar processos pedagógicos que confluem para uma mesma vertente quando cursos diferentes participam de uma mesma etapa de elaboração do saber? Esta indagação compreende um ponto nevrálgico no PIBID interdisciplinar, pois perpassa as ações desenvolvidas pelos bolsistas. A dualidade, planejamento-execução, ocorre sobre visões distintas que surgem com a gama de diversidade dos cursos presentes no PIBID. São visões que se muitas das vezes se chocam entre si, conseguem encontrar caminhos que dialogam para um entendimento de como solucionar as discórdias teóricas pertinentes nos processos pedagógicos.

Quando bolsistas estão inseridos na prática escolar, a dedicação nas situações faz surgir barreiras a serem transpostas, desafios estes, que foram sendo solucionados nos procedimentos pedagógicos das experiências na escola. Experiências estas, que serão relatadas a partir de agora, em forma da execução das atividades planejadas.

Para Delorme (2012), é nos momentos de brincadeira que as crianças podem nos informar como elas são e o que elas acreditam e vivenciam juntamente com os adultos que as cercam e, principalmente, como elas entendem o mundo ao seu redor. Os momentos das ações, propiciou tanto para as crianças quanto para nós bolsistas, aprendizagens riquíssimas.

Nós, bolsistas, procuramos desenvolver com os alunos atividades lúdicas, que chamassem suas atenções, pois desta forma, o aluno interage mais, se sente mais seguro e aprende brincando.

Brincar favorece a auto-estima, a interação com seus pares e, sobretudo, a linguagem interrogativa, propiciando situações de aprendizagem que desafiam seus saberes estabelecidos e destes fazem elementos para novos esquemas de cognição. Através do jogo simbólico a criança aprende a agir e desenvolve autonomia que possibilita descobertas e anima a exploração, a experiência e a criatividade (ANTUNES, 2004, p.32).

Foram realizadas doze atividades durante todo o ano de 2017, que tiveram como temática, o objetivo e a justifica da proposta do PIBID interdisciplinar, "A 
educação ambiental na perspectiva da promoção da saúde como eixo articulador da formação interdisciplinar". A temática foi desenvolvida buscando uma conscientização crítica, refletida no espaço escolar e buscando transpor-se para a vida social ampla das crianças, mediada através de diálogos que foram ancorados em cientificidade. Como afirma Segura:

Para a EA vista como aposta de vida, prática cidadã e construção cotidiana de uma nova sociedade, este conceito parece mais "iluminado" de sentido pois estabelece uma série de outras conexões importantes: a relação eu-nós pressupõe envolvimento solidariedade e a própria participação. Poderia ter escolhida "conscientização" ou "sensibilização", talvez as expressões mais citadas quando se fala em EA, mais foi buscada no conceito de pertencimento uma síntese dessas duas idéias (SEGURA, 2001, p.48).

As atividades que aqui chamar-se-ão de experiências, formam os relatos pedagógicos que serão transcritos. São atividades que no ato da execução transpõem a gênese do planejamento para a práxis. Serão descritas em ordem de realização cronológica, e formam o objeto relacional entre bolsistas e crianças que é investigado no trabalho.

\subsection{Atividade 'Higiene Pessoal'}

Relevância justificada porque, nós bolsistas, pudemos perceber a necessidade de tratar com os alunos sobre um tema que, dada as devidas condições sociais das crianças, é de suma importância. Realizada com as turmas do $1^{\circ}$ ao $5^{\circ}$ ano, a atividade foi pensada a partir do momento em que se constatou que as crianças possuíam aparência de uma higiene debilitada. Em muitos casos, crianças chegavam na escola sem condições mínimas de higiene. Disso, viu-se, o quanto as crianças precisavam aprender sobre a importância para a saúde de uma higiene pessoal bem realizada.

Foi bastante importante a realização da atividade, causando nas crianças uma reflexão significativa. Através de exposições orais e de vídeos, abordou-se o assunto, onde na interação entre bolsistas e crianças, perguntas destas surgiram, e foram sendo respondidas no transcorrer da manhã que se desenvolveu a ação. A atividade serviu para que as crianças tivessem conhecimento e começassem a praticar hábitos saudáveis de higiene.

No próprio andamento da atividade, constatou-se que os conteúdos abordados deveriam ser explorados com mais rigor e estímulo pela equipe pedagógica da escola, haja vista que muitos alunos não têm esse aprendizado em casa. Tal constatação foi encaminhada à equipe pedagógica da escola, para que a equipe pudesse conceber orientações as crianças sobre a importância de se ter uma saudável higiene pessoal.

\subsection{Atividade 'Alimentação Saudável'}


Integrando as turmas do $1^{\circ}$ ao $5^{\circ}$ ano, a ação partiu da necessidade de se trabalhar esse assunto, devido ao horário de $07 \mathrm{~h}$ da manhã que as crianças chegam para a aula. Ao verificar que as crianças chegavam comendo salgados com refrigerante num horário como este, constatou-se que seria necessário conscientizá-las a praticar uma alimentação saudável, mesmo que isso recorresse em 'comprar briga com a praticidade', pois a comodidade para os pais comprarem um lanche industrializado ao invés de prepará-lo em casa para os filhos, certamente é uma resposta rápida.

Esta atividade se deu com um diálogo fazendo contraponto e demonstrando através de material técnico-cientifico o que acontece com alguém que não faz uso de alimentação saudável. Os alunos interagiram bastante contando o que realmente gostavam de comer e o que de fato consumiam diariamente. Através disso, nós bolsistas, percebemos como os alunos se alimentavam de maneira inadequada, num hábito de consumo frequente. Desse modo, a conversação com os alunos se deu nas prováveis consequências que uma má alimentação pode causar na vida das pessoas.

A maioria das crianças ficou surpresa com o exposto, se comprometendo a falar com os pais para haver uma mudança na alimentação da casa, fazendo uso de uma dieta saudável. A educação alimentar foi um diálogo que visou contribuir para que os alunos levassem a seus pais a influência e importância de uma alimentação balanceada para a saúde física e neurológica dos membros das famílias.

\subsection{Atividade 'dos Sentidos'}

Executada com alunos do $1^{\circ}$ ao $3^{\circ}$ ano, fazendo uso dos sentidos, as crianças deveriam identificar diferentes tipos de alimentos. A atividade foi proposta como um espécime de extensão da atividade da 'Alimentação Saudável'. A proposta era que alunos aguçassem os sentidos para descobrir que tipo de alimento era aquele que estavam cheirando. A atividade se desenvolveu num ambiente de curiosidade e entretenimento, onde os alunos se divertiram e interagiram com muitos sorrisos.

Essa prática educativa se deu por meio do incentivo e engajamento, auxiliando os alunos e explicando a importância daquele aprendizado para o processo de maturação. A avaliação foi de que a atividade conseguiu ter êxito prático, ao demonstrar alimentos saudáveis, buscando ampliar a conscientização do que já havia sido iniciada na atividade da 'Alimentação Saudável'.

Figura 1 - Desenvolvimento da atividade 'dos Sentidos'. 


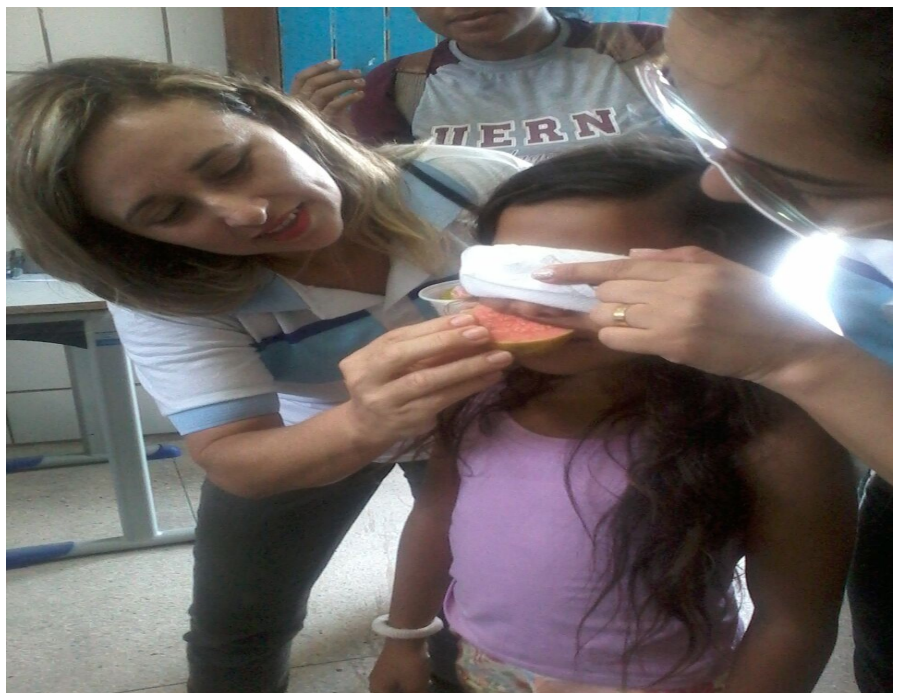

Fonte: acervo da pesquisa.

\subsection{Atividade 'Jogo dos Pratos'}

Figura 2 - Desenvolvimento da atividade 'Jogo dos Pratos'.

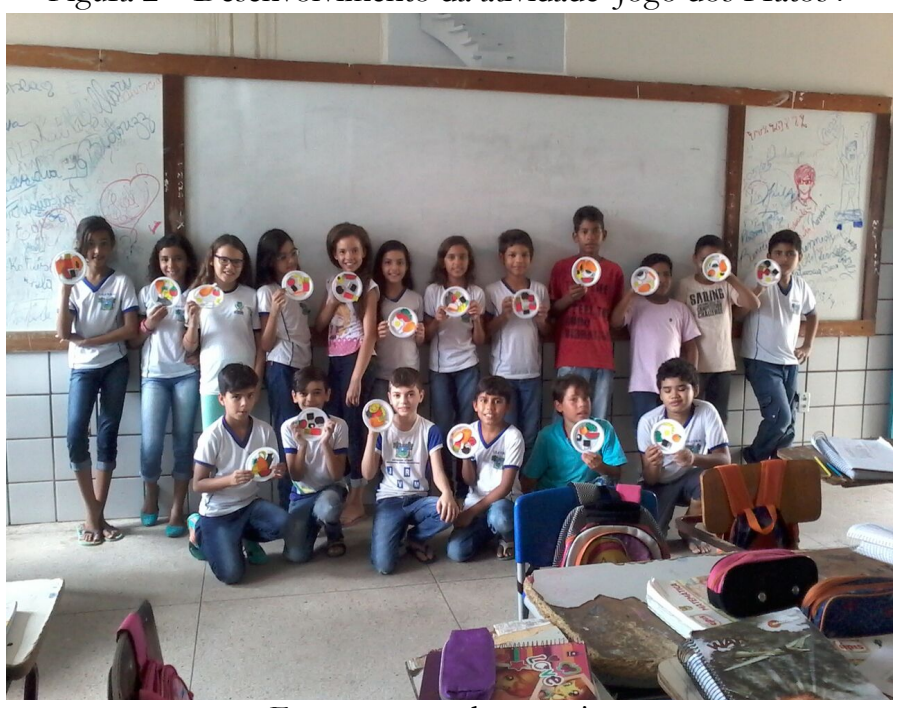

Fonte: acervo da pesquisa.

Desenvolvida com alunos do $4^{\circ}$ e $5^{\circ}$ ano, assim como a atividade 'dos Sentidos', a do 'Jogo dos Pratos' também foi uma espécie de extensão da atividade da 'Alimentação Saudável'. Cada aluno deveria colocar no prato cinco alimentos mais consumidos durante a semana. A proposta tinha o intuito de fazer com que as crianças percebessem o grau de alimentação saudável que possuíam. O resultado mostrou que a prática da alimentação saudável das crianças ainda era um exercício contumaz a ser aprimorado, visto que os alimentos elencados nos pratos não constituíam, em sua maioria, uma dieta saudável.

Ao término da atividade, o diálogo foi exortado, onde, nós bolsistas, mais uma vez, lembramos sobre a conscientização de se ter uma dieta saudável, enfatizando o uso do material técnico-cientifico que fora usado na atividade da 'Alimentação Saudável'. Material que continha consistência teórica sobre a necessidade de se fazer 
uso de uma alimentação verdadeiramente saudável. Tal recurso metodológico teve uma grande contribuição, pois o uso do material serviu para reforçar uma didática de táticas educativas em sala de aula.

\subsection{Atividade sobre 'Bullying'}

A ação foi pensada a partir de relatos que chegaram de crianças que foram vítimas de bullying. $\mathrm{Na}$ realização da ação, com as turmas do $4^{\circ}$ e $5^{\circ}$ ano, foi apresentado o filme, "Um grito de socorro", que acabou causando impacto emocional nas crianças. A proposta era que com o filme os alunos pudessem perceber a importância do respeito para com o outro.

Ao termino da exibição do filme, foi aberto diálogo, onde algumas crianças chegaram a relatar que já haviam tanto praticado quanto sofrido bullying em casa e na escola. Por ser um tema pertinente, os alunos se envolveram no diálogo, relatando seus anseios, medos, experiências e frustrações com casos de bullying. Os sentimentos, aflorados como ficaram, acabaram tomando de conta da ação, através do que era relatado.

Como é uma temática sensível no ambiente escolar, abordar o bullying foi crucial. Um dos elementos produtivos no PIBID interdisciplinar é que os diferentes cursos se intercalam nas discussões das temáticas escolhidas, e posteriormente, as discussões confluem para a ação em si. No término da atividade se chegou à conclusão de que os relatos de bullying deveriam ser repassados para a coordenação pedagógica da escola para que alguma ação conscientizadora fosse feita em relação a prevenção do bullying, tendo impactos tanto na escola como na vida social dos alunos.

\subsection{Atividade 'Semana do Meio Ambiente'}

Integrada com toda escola, a ação teve como objetivo alertar os alunos para os cuidados com a conservação ao meio ambiente, buscando sensibilizá-los sobre os cuidados com a natureza, desenvolvendo neles, responsabilidades. No ato da ação surgiu a proposta de que plantas fossem cultivadas para que as crianças regassem e as protegessem.

As plantas foram providenciadas junto a coordenação do PIBID e da escola, e alguns dias após a execução da ação, dez mudas foram plantadas no interior da escola, onde começaram a ser semeadas, ficando acordado que os alunos as regariam, acordo que foi sendo desenvolvido ao longo das semanas, resultando no crescimento das plantas.

\subsection{Atividade 'Medo de Sapo? Eu não!'}

A iniciativa ocorreu com as turmas do $1^{\circ}$ ao $5^{\circ}$ ano, surgiu quando foi visto que as crianças costumavam maltratar sapos que tinham na escola. O objetivo da iniciativa foi apelar a consciência dos alunos para a importância dos sapos na natureza. $\mathrm{Na}$ realização da tarefa, foram expostos sapos na fase de metamorfose, e um em espécie viva, e ainda sapos confeccionados com biscuit. Fazendo uso de cartazes 
informativos e dialogando com as crianças, a tarefa foi realizada nas salas de aula, onde as crianças foram fazendo perguntas que foram sendo respondidas pelos bolsistas.

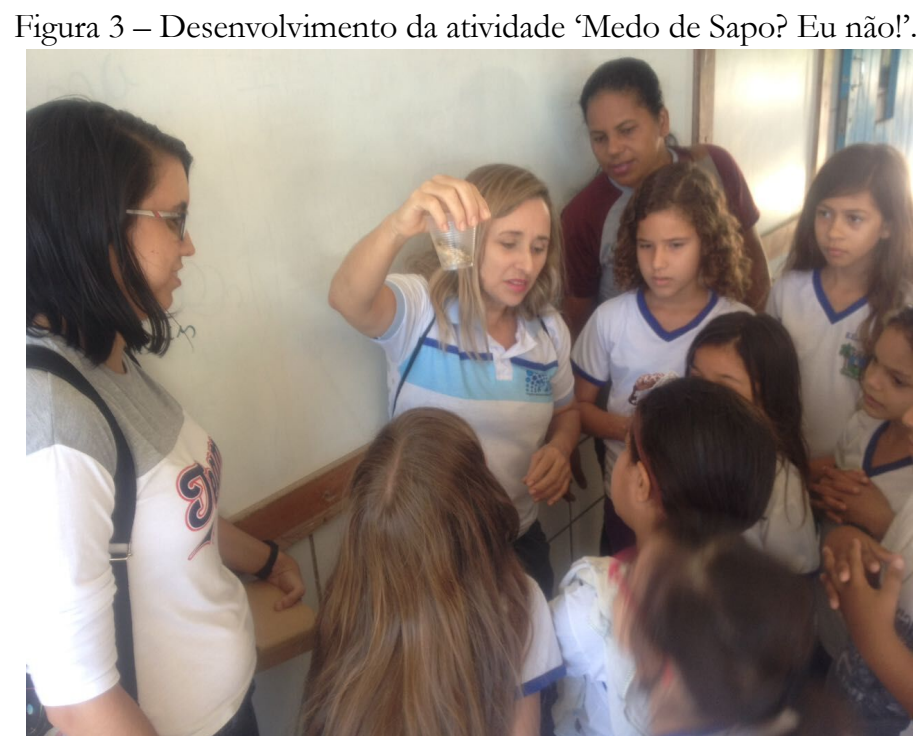

Fonte: acervo da pesquisa

\subsection{Atividade 'Cuidados no São João'}

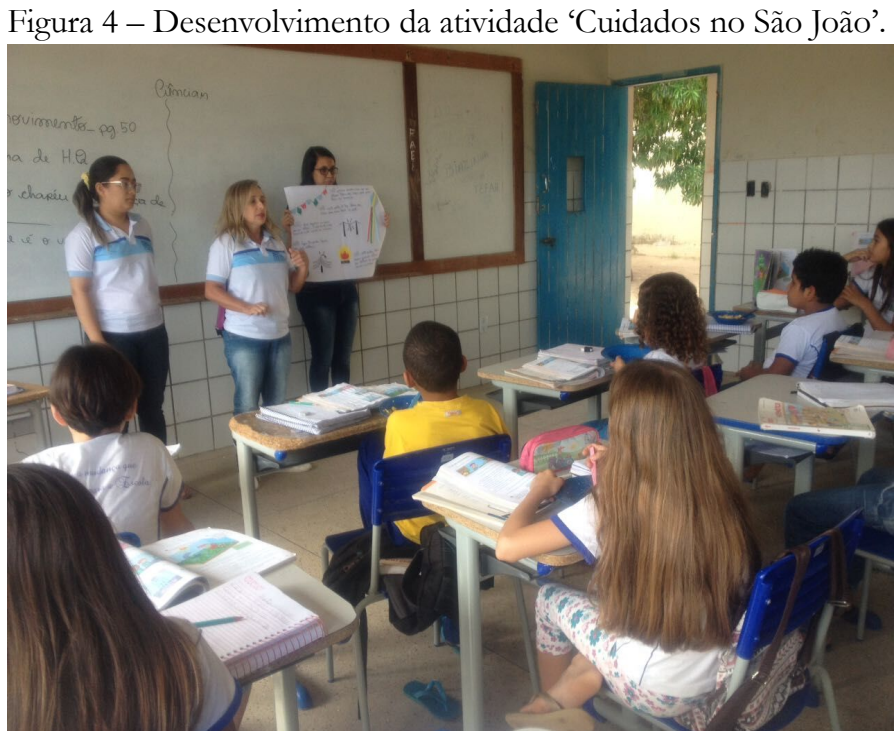

Fonte: acervo da pesquisa.

A atividade teve como base, informar sobre os cuidados acerca dos perigos com fogueiras e fogos de artifício, visto que durante o diálogo com as crianças, soubemos a partir de suas falas, o que seus familiares praticavam no período junino, onde na maioria das vezes, jogavam fogos de artificio e/ou bombinhas perto de eletricidade por possuírem falta de informação. Foi gratificante executar a atividade, pois pôde-se fazer com que os alunos pudessem refletir sobre o que estavam fazendo e levar essa reflexão para casa para ser compartilhada junto com seus familiares. 
A atividade foi desenvolvida com as turmas do $1^{\circ}$ ao $5^{\circ}$ ano. Foram preparados cartazes informativos sobre os cuidados que se deve ter com os fogos e as fogueiras. Aproveitou-se o intervalo para o desenvolvimento de objetos a partir de materiais recicláveis, relacionados com a temática junina. As crianças aproveitaram o clima junino, e algumas no decorrer do intervalo improvisaram danças de São João.

\subsection{Atividade 'Boneco Cabeça de Grama'}

Tarefa executada com as turmas do $4^{\circ}$ ano, unindo a reciclagem com o plantio de mais algumas mudas, além daquelas já plantadas na atividade da 'Semana do Meio Ambiente'. Para a tarefa confeccionou-se garrafas com rostos de bonecos com furos no fundo para saída da água e com adubo, areia e alpiste. Os alunos ao longo das semanas regavam as plantas para que pudessem crescer.

O objetivo da atividade foi de conscientizar as crianças da relevância da reciclagem, com isso, se teve como ideia pensar na reciclagem unindo-a com algo que despertasse a curiosidade nas crianças, para tanto pensou-se então em fazer um boneco cabeça de grama com material reciclável e a partir dele, fazer plantio.

A tarefa buscou despertar o desenvolvimento da consciência da sustentabilidade e da preservação ao meio ambiente. Tal intervenção foi desenvolvida trazendo exemplos das consequências que os humanos causam ao meio natural quando não se tem a devida preocupação com a relação harmônica entre natureza e sociedade.

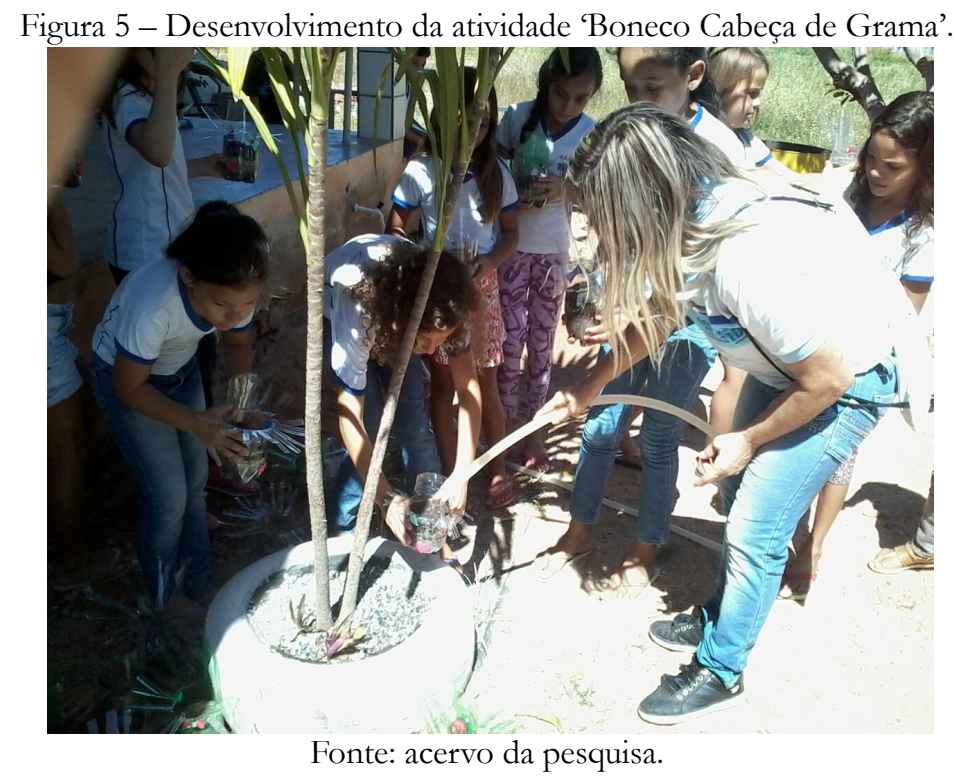

\subsection{Atividade 'Anedota Popular'}

Apresentada pelos bolsistas, com os ensaios ocorrendo na escola, a encenação da anedota se chamava, "Dois cegos briguentos", que foi apresentada na 'Semana de Arte e Cultura' da escola. Como era esperado, houve muita gargalhada das crianças e do público em geral presente na encenação, vide que a anedota possuía teor cômico. 
No entanto, apesar da comicidade da anedota, que tinha o fio condutor dos protagonistas com deficiência visual, ao fim da apresentação, abriu-se dialogo para conscientizar, sensibilizar e buscar gerar empatia nas crianças sobre a necessidade e a imprescindibilidade de acolher os colegas com deficiências. Os incluindo nas atividades na sala e na escola, integrando-os nas relações escolares.

\subsection{Atividade 'do Desenho'}

A tarefa foi feita com os alunos para apurar a opinião deles em relação aos trabalhos realizados pelo PIBID interdisciplinar. Indagando os alunos sobre quais atividades mais gostaram, e principalmente, dialogando com as crianças para ver como percebiam o PIBID na rotina escolar, servindo como um momento de reflexão entre bolsistas e crianças de todo o planejamento e execução do PIBID até aquele momento.

Com um canal de diálogo entre bolsistas e crianças, a comunicação fluiu para um debate de avaliação das perspectivas e limites do PIBID na escola. Esse episódio, foi muito construtivo para nós bolsistas, uma vez que percebemos as contribuições que deixamos para os alunos.

Os recursos metodológicos utilizados nas diferentes ações na escola tiveram um teor de aprendizagem que podem repercutir ao longo da vida escolar das crianças. Assim, salientamos a imprescindibilidade do PIBID na formação docente, pois é por meio da prática de atividades, seja na escola ou especificamente dentro da sala de aula, que superamos nossas carências e nos tornamos profissionais mais qualificados.

\subsection{Atividade 'Cantata de Natal'}

Pensada para o encerramento das aulas na escola, no momento da confraternização do último dia de aula do ano, a cantata foi planejada para ser um momento de congregação entre professores, equipe gestora e demais servidores, alunos e seus responsáveis. Foram escolhidas as músicas "Marcas do que se foi" e "Vem chegando o natal", para serem dançadas. Os ensaios foram realizados com as crianças das turmas do $4^{\circ}$ e $5^{\circ}$ ano. Os ensaios para não parecerem cansativos, foram transformados numa espécie de lazer no pátio da instituição.

A apresentação transcorreu em clima festivo, congregando todo o ano escolar. Além da equipe gestora e dos professores, também estavam presentes na encenação da cantata as mães das crianças. As outras turmas, também realizaram atividades e encenações para comemorar o espirito natalino.

Figura 6 - Momentos antes da apresentação da atividade 'Cantata de Natal'.

Rev. Caminhos da Educação: diálogos, culturas e diversidades, Teresina, v. 2, n. 3, p. 152- 


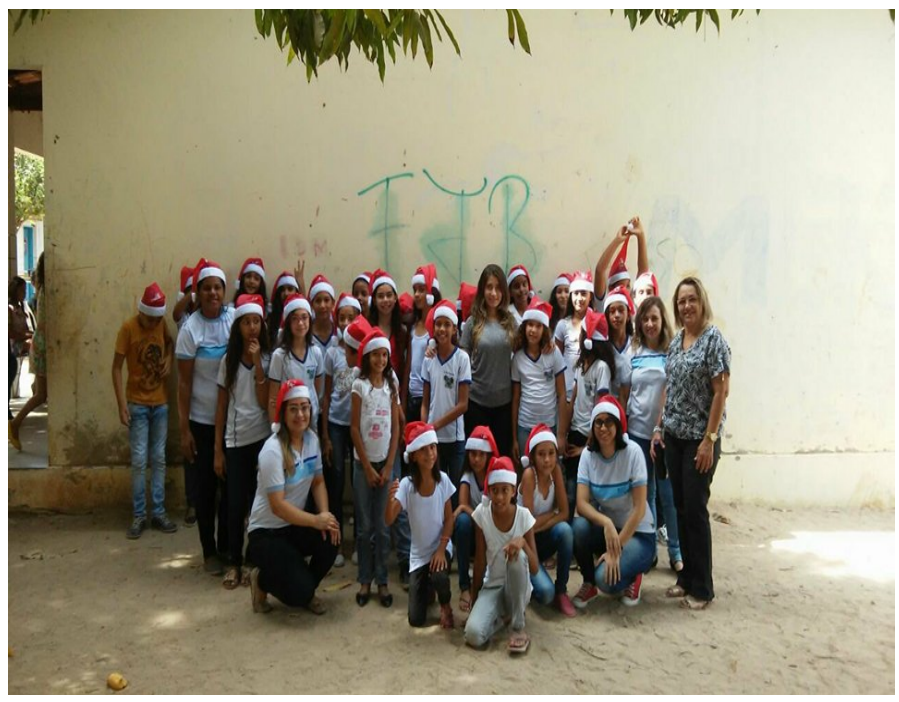

Fonte: acervo da pesquisa.

\section{Considerações finais}

A pesquisa teve como ponto de partida responder a duas indagações, o impacto das experiências na escola Jerônimo Vingt Rosado na formação docente dos bolsistas, e a diversidade de graduandos de cursos diferentes resultando em trocas de ensino-aprendizagem entre bolsistas e crianças. Propôs-se conduzir a pesquisa a partir das experiências na escola, pois compreende-se que as atividades desenvolvidas pelo PIBID foram o motor ativo pedagógico de realização do projeto Interdisciplinar na instituição. A interação entre bolsistas e crianças constituiu cerne teórico do objeto analisado, justamente por recair na faceta ímpar onde bolsistas e crianças se unem e encontram o caráter pedagógico da presença do PIBID na escola. A vivência do programa foi de pulsante energia para contribuir a pedagogia na instituição. As experiências das atividades, que aqui serviram como relatos pedagógicos, são a liga que fazem com que bolsistas e crianças, possam se fundirem numa perspectiva educacional para atingir qualidade no ensino-aprendizagem.

A formação docente sendo o desafio que é no Brasil, encontra nesse contato do universitário com a escola, por meio do PIBID, a manifestação da docência no seu ambiente genuinamente de atuação, o espaço escolar. É a manifestação da teoria das aulas se encontrando com a prática escolar, formando a dialética da práxis. Contribuindo, de sobremodo, para a formação dos bolsistas do PIBID na escola Jerônimo Vingt Rosado Maia, como professores dotados de senso crítico e se preparando para os desafios educacionais que virão. Como afirma Schmied-Kowarzid:

Cada vez mais, também a prática educacional é presa de processos de socialização e obrigações sistêmicas "naturalmente" desenvolvidas, de tal modo que os indivíduos, em vez de serem formados como portadores autônomos da práxis social, são determinados como portadores funcionais das relações sociais tomadas como dadas. Portanto, a teoria não pode se vincular diretamente de modo positivo e afirmativo a uma prática de socialização anterior, esclarecendo-a acerca de sua base ética, para fornecer desta maneira ao educador possibilidades de uma orientação e realização consciente de sua prática. Ela precisa, em 
primeiro lugar, revelar analiticamente de modo crítico as contradições sociais, os momentos da alienação na práxis educacional e de socialização anteriores, para desta maneira criar a pré-condição teoricamente consciente para uma revolução prática desta alienação (SCHMIEDKOWARZID, 1983, p.133).

Outro determinante na experiência do PIBID na escola Jerônimo Vingt Rosado Maia é o caráter diversificado dos cursos de onde advêm os bolsistas. Atuando no Ensino Fundamental I, o diálogo entre diversidade e séries iniciais, confluiu para um processo mútuo de ensino-aprendizagem. Num momento em que cursos de Ciências Biológicas e Sociais, de Geografia e Pedagogia se encontram sob um mesmo espaço de atuação para pensar e executar ideias com crianças, abre-se um leque de possiblidades onde os bolsistas se veem iniciando suas jornadas no magistério, aprendendo com visões distintas nas experiências, encarando a prática dialogando com a teoria.

\begin{abstract}
Aprendizagem é efetivada pelas trocas sociais, onde a mediação tornase relevante. Quanto mais profícua for essa ligação, maiores serão as condições de o estudante desenvolver-se. A ação do mediador não é a de facilitar porque mediar processos de aprendizagem é, sem sombras de dúvidas, provocar, trazer desafios, motivar quem vai aprender. Um dos principais escopos da mediação é criar vínculos entre educando, o professor e o espaço escolar (CUNHA, 2012, p.82).
\end{abstract}

Fica o registro de grandes lições vivenciadas no PIBID interdisciplinar, lições que repercutem na formação pessoal, e dos impactos do PIBID nos contextos profissional e formativo-acadêmico. $\mathrm{Na}$ formação pessoal se compreende que os bolsistas com suas singularidades enquanto sujeitos foram impactados pessoalmente na repercussão das experiências de sociabilidade presente nas trocas relacionais envolvidas na interação entre as crianças. Ao constatar a vulnerabilidade social destas, não há como não formar um caráter mais humano, digno e respeitoso.

$\mathrm{Na}$ relação bolsistas-alunos, a empatia foi característica essencial para encaminhar um caráter na formação pessoal dos bolsistas. No que concerne aos contextos profissional e formativo, pôde-se compreender que a formação docente foi sendo paulatinamente concebida nas experiências dos relatos pedagógicos, estruturados nos momentos de planejamento, e da execução das ações. É a escola e o PIBID interdisciplinar sendo atores do contexto formativo-profissional, esboçando desse modo a constituição da docência nos bolsistas.

As atividades relatadas no presente artigo, se deram num momento em que o PIBID sofria profundos cortes instituições no seu orçamento, onde já se sabia de antemão, que no 'novo' PIBID que viria a partir do segundo semestre de 2018, o eixo estruturante interdisciplinar não mais estaria presente no programa. Num momento em que a ciência do país caminha com enormes dificuldades estruturais, é de suma importância relatar as experiências de bolsistas do PIBID interdisciplinar na escola Estadual Jerônimo Vingt Rosado Maia. Nesses relatos pedagógicos fundamentam-se formações acadêmica, pedagógica, de magistério e de caráter de sujeitos envolvidos nas trocas de experiências, que confirmam quão valiosa é a presença do PIBID nas universidades e escolas-parceiras. 


\section{Referências}

BRASIL. Decreto n. 7219, de 24 de junho de 2010. Dispõe sobre o Programa Institucional de Bolsa de Iniciação à Docência - PIBID e dá outras providências. Diário Oficial da União, Brasília, DF, 24 jun. 2010. Disponível em: [http://www.planalto.gov.br/ccivil_03/_Ato2007-2010/2010/Decreto/D7219.htm] Acesso em: 12 fev. 2018.

Edital ño 061/2013. Brasília: Fundação Coordenação de Aperfeiçoamento de Pessoal de Nível Superior, 2013.

Subprojeto Interdisciplinar. Mossoró: Universidade do Estado do Rio Grande do Norte, 2013.

ANTUNES, C. Educação infantil: Prioridade Imprescindível. 4. ed. Rio de Janeiro: Vozes, 2004.

BAQUERO, R. Vygotsky e a aprendizagem escolar. 1. ed. Porto Alegre: Artes Médicas, 2001.

BONDÍA, J. L. Notas sobre a experiência e o saber da experiência. Revista Brasileira de Educaşão, Rio de Janeiro, s/v, n. 19, p. 20-28, 2002.

CLANDININ, D. J.; CONNELY, F. M. Pesquisa narrativa: experiencia e história em pesquisa qualitativa. 1. ed. Uberlândia: EDUFU, 2011.

COIMBRA, A. S. O tratamento da educação ambiental nas conferencias ambientais e a questão da transversalidade. Revista Eletrônica do Mestrado em Educação Ambiental, Rio Grande, v. 16, s/n, p.131-140, 2006.

CORSARO, W. A. Reprodução interpretativa e cultura de pares. In: MÜLLER, F; CARVALHO, A. M. A. Teoria e prática na pesquisa com crianças: diálogos com William Corsaro. 1. ed. São Paulo: Cortez, 2009. P.31-50.

CUNHA, A. E. Praticas Pedagógicas para a inclusão e diversidade. 2.ed. Rio de Janeiro: Wak, 2012.

DELORME, M. I. C. Infância e ludicidade. In: Maria Inês de Carvalho Delorme. Educação Infantil 2. 1. ed. Rio de Janeiro: Fundação CECIERJ, 2010. P.111-122.

EMERENCIANA, M. S. J. Reflexões sobre o homem e sua educação. Epistème, Porto Alegre, v.2, n.1, p.125-141, 1996.

FACCI, M. G. D. A periodização do desenvolvimento psicológico individual na perspectiva de Leontiev, Elkonin e Vigostki. Cadernos CEDES, Campinas, v. 24, n. 62, p.64-81, 2004.

FREIRE, P. Pedagogia da autonomia: saberes necessários à prática educativa. 2. ed. São Paulo: Paz e Terra, 1996.

FREIRE, P. Conscientização: teoria e prática da libertação: uma introdução ao pensamento de Paulo Freire. 1. ed. São Paulo: Cortez e Moraes, 1979.

Rev. Caminhos da Educação: diálogos, culturas e diversidades, Teresina, v. 2, n. 3, p. 152- 170 171, set./dez. 2020 
GONZÁLEZ REY, F. L. Epistemología cualitativa y subjetividad. 1. ed. La Habana: Editorial Pueblo y Educación, 1997.

PHILIPPI JUNIOR, A.; TUCCI, C. E. M.; HOGAN, D. J.; NAVEGANTES, R. Interdisciplinaridade em ciências ambientais. 1. ed. São Paulo: Signus, 2000.

MARINHO, A. M. S. A educação ambiental e o desafio da interdisciplinaridade. 2004. 117 f. Dissertação. (Mestrado em Educação) - Pontifícia Universidade Católica de Minas Gerais, Belo Horizonte, 2004.

PARRAT-DAYAN, S. Como enfrentar a indisciplina na escola. 1. ed. São Paulo: Contexto, 2008.

PAUliLO, M. A. S. A Pesquisa Qualitativa e a História de Vida. Serviço Social em Revista, Londrina, v. 2, n. 1, p.135-145, 1999.

PIMENTA, S. G.; LIMA, M. S. L. Estágio e docência. 2. ed. São Paulo: Cortez, 2004.

SCHMIED-KOWARZIK, W. Pedagogia dialética: de Aristóteles a Paulo Freire. 1. ed. São Paulo: Brasiliense, 1983.

SEGURA, D. S. B. Educaşão ambiental na escola pública: da curiosidade ingênua à consciência crítica. 1. ed. São Paulo: Annablume, 2001.

TARDIF, M. Saberes docentes e formação profissional. 8. ed. Petrópolis: Vozes, 2007.

VIGOTSKII, L. S.; LURIA, A. R.; LEONTIEV, A. N. Linguagem, desenvolvimento e aprendizagem. 11. ed. São Paulo: Ícone, 2010.

ZABALA, A. A prática educativa: como ensinar. 2. ed. Porto Alegre: ArtMed, 1998. 